\title{
Fatigue Properties of a Titanium Alloy (Ti-6Al-4V) Fabricated Via Electron Beam Melting (EBM): Effects of Internal Defects and Residual Stress*
}

Nikolas Hrabe (corresponding author, nik.hrabe@ @ist.gov, phone 303-497-3424, fax 303-4976682) $)^{\mathrm{a}}$, Thomas Gnäupel-Herold (thomas.gnaeupel-herold@nist.gov) ${ }^{\mathrm{b}}$, Timothy Quinn (timothy.quinn@nist.gov) $^{\mathrm{a}}$

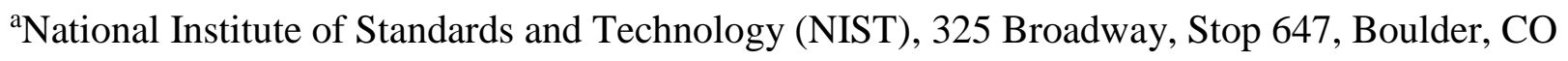
80305-3328 USA

${ }^{\mathrm{b}}$ National Institute of Standards and Technology (NIST), Center for Neutron Research, Stop 6102, Gaithersburg, MD 20899-6102 USA

*Official contribution of the National Institute of Standards and Technology; not subject to copyright in the United States.

\begin{abstract}
A clear understanding of the fatigue properties of Ti-6Al- $4 \mathrm{~V}$ manufactured with electron beam melting $(\mathrm{EBM})$ is needed to ensure performance in critical applications in the medical device and aerospace industries. In this work, the effects of residual stress and internal defects (pores and voids) on fatigue properties of EBM Ti-6Al-4V material in as-built, stress-relieved, and hot isostatic pressed (HIPed) conditions were evaluated. Conventional techniques were used to measure the chemical composition and quantify microstructures, and neutron scattering was utilized to measure residual stresses. Post-processing did not alter chemical composition. Compared to the as-built condition, microstructure was unchanged for stress-relieved material and coarser for HIPed material. No significant residual stresses were measured for any of the three conditions. This indicates build platform and layer preheating lead to sufficient process
\end{abstract}


temperatures to achieve full stress relief in-situ. The fatigue strengths at $10^{7}$ cycles measured for the as-built and stress-relieved conditions were statistically similar and were measured to be 200 $\mathrm{MPa}$ to $250 \mathrm{MPa}$. A significantly higher fatigue strength at $10^{7}$ cycles of $550 \mathrm{MPa}$ to $600 \mathrm{MPa}$ was measured for the HIPed condition. The increase in fatigue endurance limit was attributed to a reduction in internal porosity and void content.

\section{KEYWORDS}

Additive manufacturing; electron beam melting (EBM); fatigue; titanium alloy; residual stress

\section{INTRODUCTION}

Electron beam melting (EBM), an additive manufacturing process, shows great promise for making medical devices and aerospace components through excellent shape control via computer aided design input. In these industries, it is of the utmost importance to characterize and fully understand all influences on the fatigue properties as components are exposed to fatigue loading, which could lead to fatigue failures [1].

In previous EBM Ti-6Al-4V work, hot isostatic pressing (HIPing) has been shown to close internal porosity and improve fatigue endurance limit by approximately $20 \%$ [2]. Until now, it was assumed that this improvement in fatigue properties was due solely to closure of stress-concentrating internal pores, but it is possible that other microstructural changes, such as residual stress relief, are occurring during HIPing and contribute to the improvement in fatigue properties. Residual stresses are known to affect Ti-6Al-4V fatigue properties both beneficially (compressive residual stresses) and deleteriously (tensile residual stresses) [4]. It is likely that the rapid heating and cooling of additive manufacturing processes [5] create residual stresses in 
as-built material. This has been predicted by theoretical modeling of additive manufacturing processes $[6,7]$ as well as experimentally verified in laser-based additively manufactured material [6]. Previous experimental and numerical modeling results showed that build platform and powder layer preheating reduces residual stresses and negative effects such as part warping [6].

In the EBM process, the build platform is heated to approximately $700{ }^{\circ} \mathrm{C}$ before the build begins, and each layer of powder is preheated before melting, leading to a minimum process temperature of approximately $600{ }^{\circ} \mathrm{C}$ that is maintained throughout the build [8]. Full stress relief is achieved in approximately $5 \mathrm{~h}$ at this temperature according to literature [4], and EBM builds commonly run much longer than this. Therefore, it is likely that complete residual stress relief occurs during building. To our knowledge, residual stresses have not been experimentally measured for EBM Ti-6Al-4V.

In this work, we will measure relative effects of residual stress relief and internal pore/void closure on the fatigue properties of EBM Ti-6Al-4V material in the as-built, HIPed, and stress relieved conditions. It is expected that both internal pores/voids and residual stresses will be present in the as-built condition, but both will be absent from the HIPed condition. Thermal stress relieving will be used to create a condition with no residual stresses without affecting the as-built porosity of the material. The benefits of this work are twofold. First, it is of scientific import to understand and quantify all effects leading to the observed $20 \%$ increase in fatigue strength with HIPing [2]. Second, if residual stress relief results in an acceptable increase in fatigue strength, then a stress relief heat treatment could replace HIPing for fatigue critical EBM Ti-6Al-4V parts, which might provide considerable cost savings. 
It is important to note that microstructural coarsening occurs during HIPing [2] and may occur during the stress relief heat treatment. This will have an effect on the fatigue properties and should therefore be considered when interpreting the fatigue results. For equilibrium acicular or Widmanstätten microstructure, which is the expected EBM Ti-6Al-4V microstructure, the microstructural feature most commonly related to fatigue properties is $\alpha$ lath thickness, and it has been shown previously that as $\alpha$ lath thickness decreases, fatigue strength increases $[4,9,10]$. One study quantified this effect [9] and reported a $20 \%$ increase in fatigue endurance limit (approximately $500 \mathrm{MPa}$ to $600 \mathrm{MPa}$ ) for a decrease in $\alpha$ lath thickness from 10 $\mu \mathrm{m}$ to $1 \mu \mathrm{m}$.

We feel it is important to distinguish between two types of possible defects in additively manufactured (AM) metals: pores and voids. Pores are spherical with diameters on the order of the powder size used in the AM process. The shape and size of these pores indicates gas entrapment as the formation mechanism, and for EBM Ti-6Al-4V it has been previously hypothesized that hollow gas atomized powder is the source for these defects [2, 3]. Pores are considered by many to be unavoidable byproducts of AM metal processes. Voids, however, are thought of as avoidable as they are indicative of the additive process deviating from optimal melting conditions resulting in localized areas of incomplete melting. Voids are irregular in shape, tend to exist within one layer, and their size can range from hundreds of microns to much larger. Only internal pores were reported in the previous EBM Ti-6Al-4V fatigue study [2], with no mention of voids. This will be taken into consideration when comparing the results of this work to those of the previous study. 


\section{MATERIALS AND METHODS}

Sixty-four cylinders (24 mm diameter x $155 \mathrm{~mm}$ height, oriented in the $z$-direction) were built in a single build using Arcam S12 EBM equipment ${ }^{1}$ (software version 3.2.114.13836, accelerating voltage $60 \mathrm{kV}$, layer thickness $70 \mu \mathrm{m}$, speed factor 35, standard Arcam build theme for Ti-6Al-4V) and gas-atomized Ti-6Al-4V powder (average particle size $70 \mu \mathrm{m}$ ). Adjacent parts had a $1 \mathrm{~mm}$ space between them, and there was $5 \mathrm{~mm}$ spacing from the edge of the $210 \mathrm{~mm}$ x $210 \mathrm{~mm}$ build platform (Figure 1). After manufacturing, one third of the parts were stressrelieved, one third were HIPed, and one third were left in the as-built condition. Assignment of the cylinders to the three conditions was randomized to reduce the potential effect of cylinder location on the build platform. Chemistry, microstructure, and residual stress were measured for each condition in addition to tensile and fatigue testing. Results were analyzed to determine the relative effects of internal pore and void closure and residual stress relief on the fatigue properties of EBM Ti-6Al-4V. The vertical orientation (tensile/fatigue stress axis in z-direction) was chosen as it is well understood to represent the worst case [2].

Arcam build themes vary electron beam parameters (e.g., beam speed and beam current) in a controlled sequence throughout the build according to algorithms developed by the manufacturer in an effort to maintain constant heating and melt pool size. It is important to maintain constant melt pool size to achieve homogeneous microstructure and mechanical properties. Melt pool size dictates cooling rates, which in turn dictate microstructure coarseness (equilibrium acicular or Widmanstätten expected for EBM Ti-6Al-4V), and the microstructure coarseness ( $\alpha$ lath thickness) is known to dictate mechanical properties [4, 10-15].

One such algorithm of import to this work is the scan length dependency algorithm. Figure 1 aids in the explanation of this algorithm. In EBM the electron beam travels in a serpentine path, 
and the scan length is the lineal melt length between turnaround points on a given line. If there are multiple parts with non-melted space in between, all melt segments in the same line are added to determine the scan length for that line. To maintain constant heating, as scan length increases, the scan length dependency algorithm causes beam speed to increase. The algorithm also causes beam current to increase accordingly so as to maintain constant melt pool size. The EBM process allows the user to control scan length by compartmentalizing parts in what are referred to as melt models. By choosing which parts are in a given melt model, the user can achieve a desired scan length (Figure 1). For this work, all parts were included in the same melt model, resulting in scan lengths of approximately $200 \mathrm{~mm}$ for melt lines running along the diameters of the cylinders. Reasons for compartmentalizing parts to affect certain changes in scan length will be made clearer in the Discussion of this paper.

Heat treatments were performed on the as-built cylinders before any machining. The standard HIP heat treatment for Ti-6Al-4V was used $\left(2 \mathrm{~h}\right.$ at $900{ }^{\circ} \mathrm{C}$, argon, $12{ }^{\circ} \mathrm{C} / \mathrm{min}$ heating and cooling rates, $100 \mathrm{MPa}$ ) [2]. The stress relieving heat treatment used was $5 \mathrm{~h}$ at $650{ }^{\circ} \mathrm{C}$ in air followed by furnace cooling. The literature suggested that this heat treatment would lead to full stress relief [4]. This stress relief cycle was chosen to achieve full stress relief and minimize microstructural coarsening. We believed this was the most appropriate for comparison to the asbuilt condition. A stress relief cycle mimicking the HIP cycle (at atmospheric pressure) was also considered and would be interesting for future work.

Due to the affinity of titanium for oxygen and nitrogen, heat treatments are usually performed in vacuum or inert atmosphere (e.g. argon). Air was an acceptable in this work only because enough material would be removed via machining to prevent any surface chemistry effects. The results of a recent modeling study [16] showed oxygen diffusion depth of 
approximately $35 \mu \mathrm{m}$ from the surface of titanium after $420 \mathrm{~h}$ at $650{ }^{\circ} \mathrm{C}$ with an unlimited supply of oxygen.

Chemistry was measured for all three conditions and compared to ASTM F2924 (Standard Specification for Additive Manufacturing Titanium-6 Aluminum-4 Vanadium with Powder Bed Fusion [17]). The specimens used for chemistry were all taken from the same cylindrical part. Also, after heat treatment, approximately $1 \mathrm{~mm}$ was removed from each surface of each specimen by grinding with $\mathrm{SiC}$ paper to reduce surface chemistry effects. Aluminum, vanadium, and iron were measured by optical emission spectroscopy (OES). Oxygen, nitrogen, and hydrogen were measured by inert gas fusion. Carbon was measured by the combustion method. Approximate uncertainties in each measurement were as follows: oxygen (3\%), nitrogen (14\%), hydrogen (6\%), and carbon (6\%). Uncertainties for aluminum, vanadium, and iron were not available.

Microstructure for all three conditions were observed and quantitatively compared. It is important to note that EBM Ti-6Al-4V microstructure was not found to vary significantly in the $z$-direction in a previous study [18], suggesting it is appropriate to assume no effect from variation within the part on any observed changes in microstructure between the three conditions. Specimens were mounted, polished, and etched (Kroll's etchant, $2 \%$ hydrofluoric acid, $5 \%$ nitric acid, balance water). The $\alpha$ lath thickness was observed using optical microscope images and quantified with the use of Image $\mathbf{J}^{1}$ [19]. Three images were taken for each condition, and $20 \alpha$ laths were measured for each image, totaling $60 \alpha$ laths measured for each condition. It is important to note that the chosen quantification method depended on the subjective judgment of the person making the measurement, but measurement uncertainty was minimized as one person made all measurements. 
The determination of residual stresses through diffraction methods is the subject of numerous textbooks $[20,21]$. Neutron measurements were performed with a BT8 residual stress diffractometer. For each condition, one sample was cut from the approximate center of the cylinder and approximately $25 \mathrm{~mm}$ from the bottom of the cylinder using a low-speed abrasive saw to obtain sample volume of approximately $X=13 \mathrm{~mm}, \mathrm{Y}=13 \mathrm{~mm}, \mathrm{Z}=16 \mathrm{~mm}$. The purpose was to measure strains at several locations within each sample to map the threedimensional distribution of stresses. Due to the combined nuclear properties of this alloy, and of titanium as the main constituent in particular (high incoherent scattering and strong absorption), the signal-to-noise ratio of the measured peaks (hkl) was too low (2:1) to permit extensive mapping for each sample. The gage volume, within which all residual stresses are averaged for one measurement, was $4 \times 4 \times 4 \mathrm{~mm}^{3}$. The use of the feed stock powder for determining the reference $d$-spacing $d_{0}$ is a straightforward assumption; however, it was found that in this case all stresses for all samples would become tensile in nature (between $100 \mathrm{MPa}$ and $200 \mathrm{MPa}$ ). As this would violate the condition that requires the sample to be in overall force balance, it was concluded that the feed powder does not represent the reference state. As an alternative, $d_{0}$ was determined from the arithmetic average of measured $d$-spacings for each sample. One possible reason for the observed lattice parameter mismatch is the well characterized aluminum fade during electron beam melting of Ti-6Al-4V [22].

Each remaining cylindrical part was machined as threaded cylindrical test specimens that met both ASTM E8/E8M (Standard Test Methods for Tension Testing of Metallic Materials[23]) and ASTM E466 (Standard Practice for Conducting Force Controlled Constant Amplitude Axial Fatigue Tests of Metallic Materials[24]) with the following dimensions: gauge length $25.9 \mathrm{~mm}$ (1.02 inches), gauge diameter $6.35 \mathrm{~mm}$ ( 0.25 inches), and $19.1 \mathrm{~mm}$ ( 0.75 inch) coarse threads. 
Tensile testing was performed according to ASTM E8/E8M [23] for three specimens per condition at a strain rate of $10^{-3} \mathrm{~s}^{-1}$. Yield strength (YS, $0.2 \%$ offset method), percent elongation (\%EL), and ultimate tensile strength (UTS) were determined from the engineering stress-strain curve of each specimen. Tension-tension fatigue testing (room temperature, $20 \mathrm{~Hz}, R=0.1$ ) was performed for each condition according to ASTM E466 [24], and the results were plotted on stress vs. cycles-to-failure $(S-N)$ curves. The number of fatigue specimens tested at each stress level for each condition ranged from one to three. The ratio of minimum to maximum loads $(R)$ for each fatigue test was approximately $R=0.1$.

For quantitative microstructural and tensile data, nonparametric ANOVA (KruskalWallis) statistical analysis was performed for comparisons between conditions, and $p$-values less than 0.05 were considered significant. Statistical analysis comparing differences between fatigue behaviors of the three material conditions is described in more detail with the fatigue results. Fracture surfaces of both monotonic and fatigue specimens were observed using scanning electron microscopy (SEM).

\section{RESULTS}

\subsection{Chemistry}

No significant differences in chemistry were observed between the three conditions (Table I). This eliminates the possibility that differences in chemistry between the conditions would be the cause of differences in fatigue results. The mean value of nitrogen is over specification by as much as $10 \%$, but the uncertainty for this measurement was approximately $14 \%$. This potential factor should be considered when comparing the measured mechanical 
properties to similar properties from the literature. However, the difference in mean values between the three conditions is not significantly different.

\subsection{Microstructure}

The microstructures of all three conditions (Figure 2) were as expected for EBM Ti-6Al4V (equilibrium acicular or Widmanstätten). It was observed qualitatively that the stress relief heat treatment did not result in any apparent change in $\alpha$ lath thickness, but the HIPed microstructure did appear coarser compared to the as-built condition as expected from previous studies on EBM Ti-6Al-4V [2]. The $\alpha$ lath thickness measurements (Figure 3) supported these qualitative observations. Internal porosity (spherical, diameter on order of powder size) was observed in as-built and stress-relieved conditions but not in the HIPed condition as expected. This qualitatively suggests HIPing successfully closed internal porosity from hollow gas atomized powder, and these results are supported by previous helium pycnometry results quantifying the efficacy of the same HIP cycle as used in this work for EBM Ti-6Al-4V [2]. There was no apparent preferred orientation of the $\alpha$ laths with respect to the build direction.

\subsection{Residual Stress Measurements}

We interpret the residual stress results (Table II) to indicate there are no significant residual stresses in any of the three conditions, as most stress values are within two standard errors $($ standard error $=30 \mathrm{MPa}$ ) of zero and are less than $5 \%$ of the monotonic yield strength (Figure 4). Also, there is no clear distinction in the stresses for different directions $(x, y, z)$. 


\subsection{Tension Testing}

Due to the microstructure results (Figure 2 and Figure 3) and the known relationship between $\alpha$ lath thickness and tensile properties [4, 10-15], it was expected that compared to the as-built condition, stress relief would result in no change in tensile properties, and HIPed material would have lower UTS and $Y S$ and higher \%EL. In general this expectation was observed in the results (Figure 4). However, ANOVA analysis showed the difference in UTS between the as-built and HIPed condition was not significant. This ANOVA result is thought to be influenced by the relatively large standard deviations observed for both as-built and stressrelieved conditions compared to the standard deviations of the HIPed condition as well as standard deviations observed previously for EBM Ti-6Al-4V [2,25]. We believe the larger standard deviations arise from the voids observed on the fracture surfaces of all as-built and stress-relieved specimens tested.

Viewing these voids on the $x-y$ plane on fracture surfaces of tensile specimens (Figure 5) as well as perpendicular to the $x-y$ plane in cross-sections of bulk material (Figure 6) leads to some important observations. First, these voids are different in size and shape compared to internal pores from hollow gas-atomized powder. The lower surfaces of the voids (Figure 5b) are relatively flat, and we believe this is the top surface of the layer beneath the void. The upper surfaces of voids (Figure 5a) all have un-melted powder particles partially penetrated by melt from above. A potential mechanism for localized incomplete melting leading to void formation will be presented in the Discussion section of this paper.

It is important to note that voids were not observed on any of the HIPed specimens tested, qualitatively suggesting successful closure not only of internal pores but also voids. 


\subsection{Fatigue Properties}

No significant differences were observed between the fatigue behavior of as-built and stress-relieved material (fatigue strength at $10^{7}$ cycles between $200 \mathrm{MPa}$ to $250 \mathrm{MPa}$ ), but HIPed material showed over $100 \%$ improvement (fatigue strength at $10^{7}$ cycles between $550 \mathrm{MPa}$ to $600 \mathrm{MPa}$ ) compared to as-built and stress-relieved conditions (Figure 7).

We investigated the statistical significance of the difference between HIPed and asbuilt/stress-relieved, which were considered to be the same. It was assumed that all measurements are independent, the log of cycles to failure is normally distributed, and the model for S-N fatigue behavior is the correct model. Specimens that reached $10^{7}$ cycles without failure (runouts) were included as censored data. The model used for S-N fatigue behavior [26] was of the form:

$$
\log (N)=\beta_{0}+\beta_{1} S^{-\beta_{2}}+\varepsilon, \varepsilon \sim N\left(0, \sigma^{2}\right),
$$

where $N=$ cycles to failure and $S=$ normalized engineering stress (stress/max(stress)). In order to fit this curve, the profile likelihood method was used to obtain an estimate for $\beta_{2}$ utilizing code from previous work [27]. The idea is to step through a range of plausible values for $\beta_{2}$, finding the maximum of the likelihood function over the remaining parameters for each plausible value. The value with the greatest likelihood was chosen as an estimate for $\beta_{2}$ for the remainder of the analysis. We denote this fixed estimate of $\beta_{2}$ as $b_{2}$. For this data, $b_{2}=1$. In order to determine whether the HIPed data came from the same model, a parametric survival regression model was fit using an indicator variable to denote whether the data was from the HIPed data set:

$$
\log (N)=\beta_{0}+\beta_{1} S^{-b_{2}}+\beta_{3} X+\beta_{4} S^{-b_{2}} \cdot X+\varepsilon, \varepsilon \sim N\left(0, \sigma^{2}\right),
$$


where $X=1$ if the data are from HIPed and 0 otherwise. Thus, if the data are from HIPed, the fitted model is:

$$
\log (N)=\left(\beta_{0}+\beta_{3}\right)+\left(\beta_{1}+\beta_{4}\right) S^{-b_{n}}+\varepsilon, \varepsilon^{\sim} N\left(0, \sigma^{2}\right) .
$$

If the data are from either as-built or stress-relieved, the model reduces to:

$$
\log (N)=\beta_{0}+\beta_{1} S^{-b_{2}}+\varepsilon, \varepsilon \sim N\left(0, \sigma^{2}\right) .
$$

Testing whether these two models are equivalent reduces to testing whether either $\beta_{3}$ or $\beta_{4}$ differs from 0 . If the results of this test indicate either $\beta_{3}$ or $\beta_{4}$ differs from 0 , then the HIPed fatigue data is not the same as the as-built/stress-relieved fatigue data. Parameter estimates, standard deviations, and $p$-values for the model using the survreg function in R [28] are reported in Table III. Since the $p$-value for testing $H_{0}: \beta_{4}=0$ is less than 0.05 , we can reject the hypothesis that the two $S$ - $N$ curves have the same slope $(p=0.00161)$. The $S$ - $N$ curves in Figure 7 include the regression lines from the above fit for both the as-built and stress-relieved data as well as for the HIPed data (solid lines). 95\% confidence bounds on the regression fit are also included (dotted lines). It is important to note that this model was arrived at empirically for use as a design tool. Also, it applies only to high-cycle fatigue (HCF) and not low-cycle fatigue (LCF).

Voids were observed on all as-built and stress-relieved fracture surfaces, and river markings pointed to these voids as fatigue crack initiation sites (Figure 8a,b). Facets (Figure 8c) and striations (Figure 8d), characteristic of Ti-6Al-4V fatigue failure [29], were also observed on fracture surfaces of specimens for all three conditions. There was no correlation between parts with voids and position in the build space as voids were found to occur in parts covering the entire build space. Voids were not limited to a single layer within the build and were found at 
many distances from the bottom of the cylinders. Formation of voids were not an edge effect as voids were observed in the gauge section of tensile and fatigue specimens, which was at the interior of the as-built cylindrical part. Neither voids nor internal pores were observed on the fatigue fracture surfaces of HIPed specimens (Figure 9).

\section{DISCUSSION}

Neutron scattering results (Table II) suggest negligible residual stresses in all of the EBM Ti-6Al-4V conditions tested (as-built, stress-relieved, and HIPed). It is difficult to prove that there are negligible residual stresses, and the larger than desirable gage volume, necessitated by the high incoherent scattering and strong absorption of titanium, does not help. However, fatigue results and knowledge of EBM Ti-6Al-4V thermal history do support this conclusion. Fatigue results (Figure 7) showed no difference between as-built and stress-relieved conditions, which suggests residual stresses are at least small enough to have negligible effect on fatigue properties. Also, at the high background temperature from layer preheating in EBM (above approximately $\left.600{ }^{\circ} \mathrm{C}[8]\right)$, it is likely full stress relief occurs during building considering typical EBM build times are well in excess of the literature time to full stress relief at the same temperature ( $5 \mathrm{~h}$, $\left.600{ }^{\circ} \mathrm{C}[4]\right)$.

Compared to as-built and stress-relieved material, HIPed material showed a drastic improvement in fatigue strength at $10^{7}$ cycles over as-built material (more than $100 \%$ ). Because of the residual stress results of this study, we can now more conclusively attribute this improvement to closure of internal pores and voids. Chemistry results showed no significant differences between conditions (Table I) eliminating it as a variable in this work. Coarsening during HIPing (Figure 2 and Figure 3) most likely affected the fatigue results, but it was a 
deleterious effect compared to the beneficial effect of internal pore/void closure, suggesting the fatigue improvement due to internal pore/void closure is even greater than measured. The deleterious effect from coarsening is known from the results of previous work on Ti-6Al-4V, of the same microstructure as the present work, which reported an increase in fatigue endurance limit from $500 \mathrm{MPa}$ to $600 \mathrm{MPa}$ for a decrease in $\alpha$ lath thickness from $10 \mu \mathrm{m}$ to $1 \mu \mathrm{m}$ [9]. It was difficult to quantify the effect of coarsening in the present work as the specific relationship between $\alpha$ lath thickness and fatigue properties (e.g. Hall-Petch) is unknown. However, the comparatively small coarsening observed in the present work (approximately $1.6 \mu \mathrm{m}$ HIPed to $0.8 \mu \mathrm{m}$ as-built, Figure 3) gives some indication of the expected magnitude of effect on fatigue properties.

Comparing the fatigue results of this work to a similar EBM Ti-6Al-4V fatigue study (R $=0.1$ ) with z-oriented specimens, the HIPed results agree well (approximately $550 \mathrm{MPa}$ fatigue strength at $10^{7}$ cycles [2]), but our as-built fatigue strength at $10^{7}$ cycles was significantly lower (200 MPa to $250 \mathrm{MPa}$, Figure 7) than the previous study (approximately $450 \mathrm{MPa}$ [2]). We hypothesize that the reason for this difference in fatigue properties is due to a higher prevalence and severity of voids in the present work compared to the previous study [2]. This cannot be confirmed as there is no mention of voids in the previous study.

Voids were observed on all as-built and stress-relieved tensile (Figure 5 and Figure 6) and fatigue (Figure 8) specimens and were found to occur at all fatigue crack initiation sites (Figure 8a), which further supports our hypothesis. Observations of void locations and morphology suggest that voids were formed due to localized incomplete melting. The cause of incomplete melting in this case is thought to be related to the scan length dependency algorithm. As scan length increases, the scan length dependency algorithm causes beam speed and beam 
current to increase, but the EBM equipment manufacturer has set a $21 \mathrm{~mA}$ upper limit on beam current because beam quality is deemed to be unacceptable above this limit. At scan lengths of approximately $120 \mathrm{~mm}$, the $21 \mathrm{~mA}$ beam current limit is reached, and at longer scan lengths, the beam current will not be increased further, which will lead to under-melting and formation of voids [30]. The scan length in this work was as long as $200 \mathrm{~mm}$ for melt lines running through diameters of cylinders. Compartmentalizing the cylinders of the build into smaller melt models (Figure 1) would have acceptably shortened the scan length and prevented void formation [30].

Although long scan lengths were found to lead to void formation in this work, prevalence and severity of voids were the same for as-built and stress-relieved conditions. Thus, we can still compare as-built and stress-relieved conditions and determine that there is no difference in fatigue properties for these two conditions. This suggests that residual stress relief plays no role in fatigue properties of EBM Ti-6Al-4V. Without voids, the fatigue strength at $10^{7}$ cycles for the as-built material, as well as the relative improvement due to internal pore closure during HIPing, would be expected to be closer to previous results (20\% improvement, [2]).

Apart from the improvement in fatigue results, HIPing resulted in lower UTS and YS and higher \%EL (Figure 4), which was expected due to the microstructural coarsening that was observed to occur during HIPing (Figure 2 and Figure 3), as well as the known relationship between $\alpha$ lath thickness and tensile properties [4, 10-15]. This effect of HIPing should also be considered when deciding whether or not to use HIPing for EBM Ti-6Al-4V material.

\section{CONCLUSIONS}

EBM manufactured Ti-6Al-4V material was evaluated to understand the relative effects of residual stress relief and internal pore and void closure on fatigue performance. Material was 
evaluated in the as-built, stress-relieved, and HIPed conditions to separate residual stress and defect density effects. Residual stress measurements showed no significant stresses in any of the three conditions. The absence of residual stresses was attributed to high process temperatures of over $600{ }^{\circ} \mathrm{C}$, which were caused by build platform and powder layer preheating used in EBM manufacturing. The as-built and stress-relieved materials were found to be chemically and microstructurally indistinguishable. This was consistent with the measured fatigue strength at $10^{7}$ cycles, which were statistically similar at approximately $200 \mathrm{MPa}$ to $250 \mathrm{MPa}$. The HIP process did not alter the chemical composition of the material but did dramatically reduce the pore and void density of the material and induce minimal microstructural coarsening. Compared to as-built and stress relieved conditions, HIPing led to a more than $100 \%$ increase in the fatigue strength at $10^{7}$ cycles (approximately $550 \mathrm{MPa}$ to $600 \mathrm{MPa}$ ). A decrease in UTS and YS, and an increase in \% EL were also observed for the HIPed condition compared to the as-built condition. It was observed that voids were most often the source of fatigue crack initiation, and the improvement in fatigue strength is attributed to the reduction of initiation sites through internal pore and void closure during HIPing.

\section{ACKNOWLEDGMENTS}

This research was performed while the author held a National Research Council Research Associateship Award at the National Institute of Standards and Technology. The statistical analysis of fatigue results was performed by Sarah Streett of NIST. 


\section{FOOTNOTES}

${ }^{1}$ Commercial names are identified in order to specify the experimental procedure adequately. Such identification is not intended to imply recommendation or endorsement by the NIST nor does it imply that they are necessarily the best available for the purpose.

\section{REFERENCES}

[1] J.R. Davis, Handbook of Materials for Medical Devices, ASM International, Metals Park, $\mathrm{OH}, 2003$.

[2] U. Ackelid, M. Svensson, Additive Manufacturing of Dense Metal Parts by Electron Beam Melting, in: Materials Science and Technology Conference, MS\&T Partner Societies, Pittsburgh, PA, 2009, pp. 2711-2719.

[3] A. Bauereiss, T. Scharowsky, C. Koerner, Defect Generation and Propagation Mechanism During Additive Manufacturing by Selective Electron Beam Melting, J MATER PROCESS TECH, 214 (2014) 2522-2528.

[4] G. Welsch, R. Boyer, E.W. Collings, Materials Properties Handbook: Titanium Alloys, ASM International, Metals Park, OH, 1994.

[5] L. Qian, J. Mei, J. Liang, X. Wu, Influence of Position and Laser Power on Thermal History and Microstructure of Direct Laser Fabricated Ti-6Al-4V, MATER SCI TECH SER, 21 (2005) 597-605.

[6] N.W. Klingbeil, J.L. Beuth, R.K. Chin, C.H. Amon, Residual stress-induced warping in direct metal solid freeform fabrication, Int. J. Mech. Sci., 44 (2002) 57-77. 
[7] A. Vasinonta, J.L. Beuth, M. Griffith, Process maps for predicting residual stress and melt pool size in the laser-based fabrication of thin-walled structures, J. Manuf. Sci. Eng.-Trans. ASME, 129 (2007) 101-109.

[8] Arcam S12 User Guide, in, Arcam AB, Molndal, Sweden.

[9] G. Lutjering, A. Gysler, Fatigue: A Critical Review, in: G. Lutjering, U. Zwicker, W. Bunk (Eds.) Titanium '84 - Science and Technology, Deutsche Gesellschaft fur Metallkunde EV, Munich, 1985, pp. 2065-2083.

[10] H.J. Rack, J.I. Qazi, Titanium Alloys for Biomedical Applications, MAT SCI ENG C, 26 (2006) 1269-1277.

[11] E.W. Collings, The Physical Metallurgy of Titanium Alloys, American Society for Metals, Metals Park, OH, 1984.

[12] M.J. Donachie, Titanium: A Technical Guide, 2nd ed., ASM International, Metals Park, Ohio, 1989.

[13] G. Lütjering, J. Albrecht, O.M. Ivasishin, Influence of Cooling Rate and $\beta$ Grain Size on the Tensile Properties of $(\alpha+\beta)$ Ti Alloys, in: 8th World Titanium Conference Proceedings, 1995. [14] G. Lütjering, J.C. Williams, Titanium, 2nd ed., Springer, Berlin, 2007.

[15] J. Tiley, T. Searles, E. Lee, S. Kar, R. Banerjee, J.C. Russ, H. Fraser, Quantification of Microstructural Features in $\alpha / \beta$ titanium alloys, MAT SCI ENG A, 372 (2004) 191-198.

[16] R.A. Brockman, A.L. Pilchak, W.J. Porter III, R. John, Estimation of grain boundary diffusivity in near-a titanium polycrystals, SCRIPTA MATER, 65 (2011) 513-515.

[17] ASTM F2924 Standard Specification for Additive Manufacturing Titanium-6 Aluminum-4 Vanadium with Powder Bed Fusion. 
[18] N. Hrabe, T. Quinn, Effects of Processing on Microstructure and Mechanical Properties of Ti-6Al-4V Fabricated using Electron Beam Melting (EBM), Part 1: Distance from Build Plate and Part Size, MAT SCI ENG A, 573 (2013) 264-270.

[19] C.A. Schneider, W.S. Rasband, K.W. Eliceiri, NIH Image to ImageJ: 25years of image analysis, Nature Methods, 9 (2012) 671-675.

[20] V. Hauk, Structural and Residual Stress Analysis by Nondestructive Methods - Evaluation, Application, Assessment, in, Elsevier, Amsterdam, 1997.

[21] I.C. Noyan, J.B. Cohen, Residual Stress: Measurement by Diffraction and Interpretation, Springer-Verlag, New York, 1987.

[22] S.L. Semiatin, V.G. Ivanchenko, S.V. Akhonin, O.M. Ivasishin, Diffusion Models for Evaporation Losses during Electron-Beam Melting of Alpha/Beta-Titanium Alloys, METALL MATER TRANS B, 35B (2004) 235-245.

[23] ASTM E8/E8M Standard Test Methods for Tension Testing of Metallic Materials.

[24] ASTM E466 Standard Practice for Conducting Force Controlled Constant Amplitude Axial Fatigue Tests of Metallic Materials.

[25] B.S. Bass, Validating the Arcam EBM Process as an Alternative Fabrication Method for Titanium-6Al-4V Alloys, in: Materials Science and Engineering, M.S. Thesis, North Carolina State University Raleigh, NC, 2007, pp. 57.

[26] W. Nelson, Accelerated Testing: Statistical Models, Test Plans and Data Analyses, Wiley, New York, 1990.

[27] T. Haddad, A. Himes, M. Campbell, Fracture Prediction of Cardiac Lead Medical Devices Using Bayesian Networks, Reliability Engineering and Systems Safety, 123 (2014) 145-157. 
[28] R Development Core Team, R: A language and enviornment for statistical computing, in, $\mathrm{R}$ Foundation for Statistical Computing. http://www.R-project.org, 2015.

[29] A.L. Pilchak, J.C. WIlliams, Observations of Facet Formation in Near-a Titanium and Comments on the Role of Hydrogen, METALL MATER TRANS A, 42A (2011) 1000-1027. [30] M. Svensson, EBM-Manufactured Ti6Al4V ELI with EBM-Control 3.2 and Scan Length Dependency, in, Arcam AB internal report, Moldndal, Sweden, 2011.

\section{CAPTIONS for FIGURES and TABLES}

Figure 1. Build space layout of sixty-four z-oriented cylindrical parts (24 mm diameter x $155 \mathrm{~mm}$ height) on a $210 \mathrm{~mm} \times 210 \mathrm{~mm}$ build platform. There was $1 \mathrm{~mm}$ space between adjacent parts and $5 \mathrm{~mm}$ space from the edge of the build platform. Dotted black line with arrows indicates serpentine motion of electron beam. Example of melt model leading to shorter scan length is shown in top right corner of figure.

Table I. Chemistry results (in wt\%) shown for all three conditions compared to F2924. There is no significant difference in chemical composition for any of the conditions. Measurement uncertainties are shown for each element if available.

Figure 2. Optical microscope images for the (a) as-built (b) stress-relieved, and (c) HIPed conditions showing expected equilibrium acicular or Widmanstätten microstructure $(\alpha-$ lighter phase, $\beta$-darker phase). Compared to as-built microstructure, no difference is observed due to stress relief heat treatment, but HIPed microstructure appears to have coarser $\alpha$ laths. 
Figure 3. Quantitative a lath thickness results showing that microstructure coarsens during HIPing but not during stress relief heat treatment (*** indicates a significant difference, $p<0.001)$.

Table II. Residual stresses determined from the neutron measurements. The coordinates given refer to the center of each sample. The standard error is $30 \mathrm{MPa}$.

Figure 4. Tensile properties for all three conditions including ANOVA analysis results $*^{*}=$ $p<0.05, * *=p<0.01)$. In general, as expected, the stress relief heat treatment did not change tensile properties and HIPing led to lower UTS and YS and higher \% EL. However, ANOVA indicated no significant difference for UTS between as-built and HIPed.

Figure 5. Scanning electron microscope (SEM) images of (a) bottom (b) top fracture surfaces on an as-built tensile specimen showing voids (white arrows) and internal pores (black arrows). "Bottom" and "top" are in reference to the z-direction. These fracture surfaces were the worst case in terms of amount of voids, but all other aspects of the voids on these fracture surfaces are representative of all as-built and stress-relieved specimens investigated. White arrows in (a) and (b) are pointing to the same area of the same void. Uni-directional lines observed on bottom void surfaces are melt flow lines from top of previous layer, and un-melted powder particles are observed in top void surface, suggesting voids are formed due to localized incomplete melting. 
Figure 6. Optical images of voids (white arrows) observed on polished and etched cross-sections of as-built bulk material emphasizing how thin these voids are in the $z$-direction. Internal pores (black arrows) are also observed. This is representative of all as-built and stress-relieved specimens.

Figure 7. S-N curve fatigue results for all three conditions. Maximum tensile stress is plotted against cycles to failure. Arrows indicate sample did not fail (runout). No difference was observed between as-built and stress-relieved conditions, but HIPed material showed a significant improvement $(p=0.00161)$. Solid lines are from regression fit, and dotted lines are 95\% confidence bounds from regression fit.

Table III. Statistical results for S-N fatigue curve model: parameter estimates, standard errors, and p-values.

Figure 8. SEM images of as-built fatigue fracture surface: (a) internal pores (black arrows) and river marks point to void at fatigue crack initiation site (white arrow); (b,c) facets (white arrows) and $(d)$ striations (white arrow) are characteristic of Ti-6Al-4V fatigue fracture and were observed on all fracture surfaces for all conditions.

Figure 9. SEM images of HIPed fatigue fracture surface. These images are representative of HIPed fatigue fracture surfaces. (a) river marks point to initiation site at center of image, interior initiation, (b) no evidence of voids or internal pores at fatigue crack initiation. 


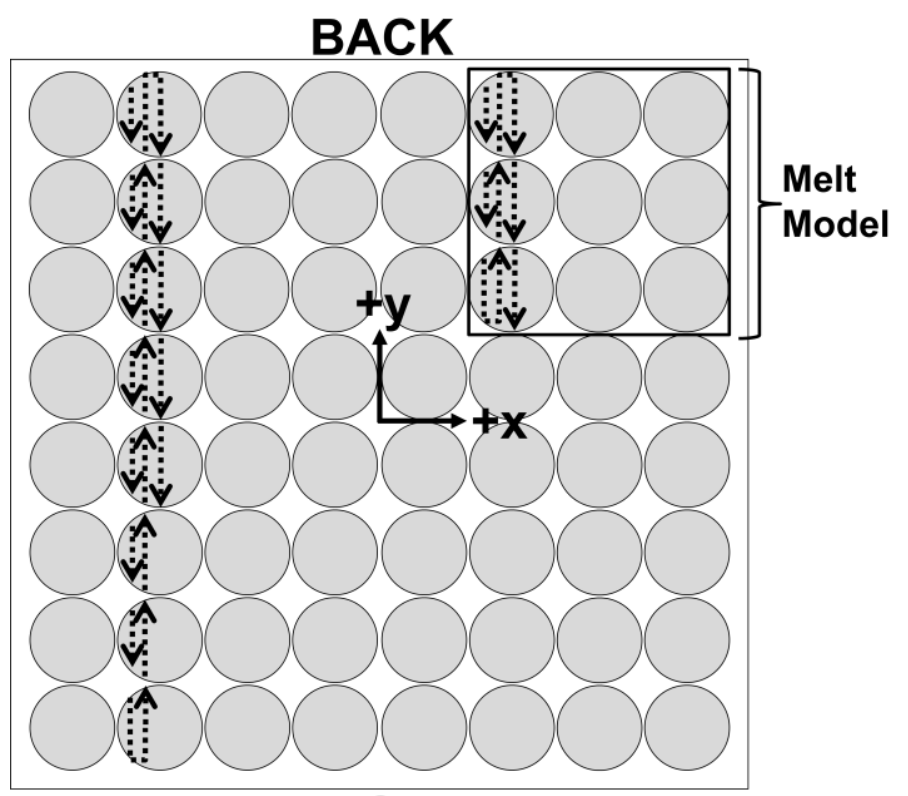

FRONT 


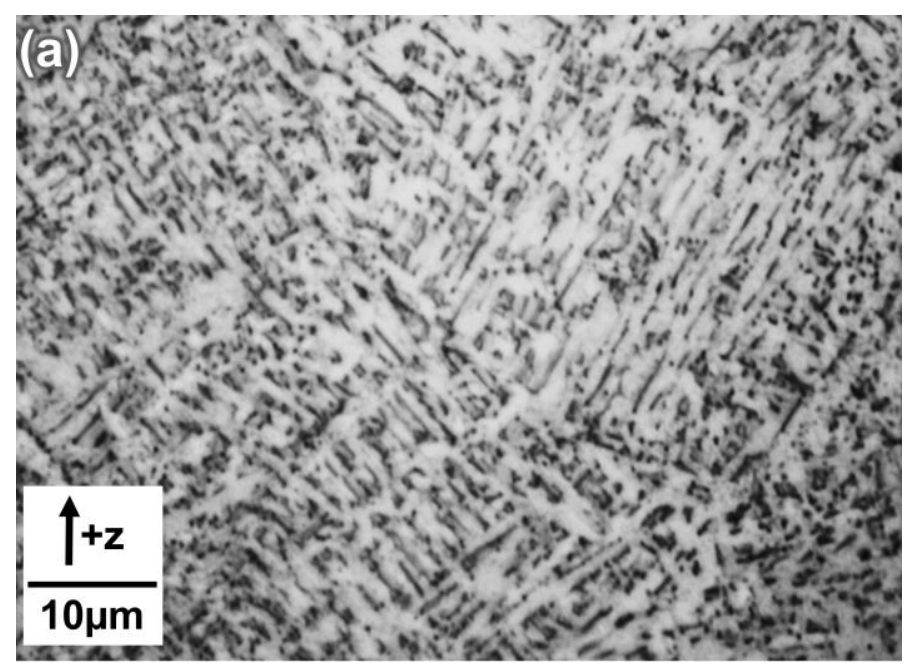

Page 25 of 41 


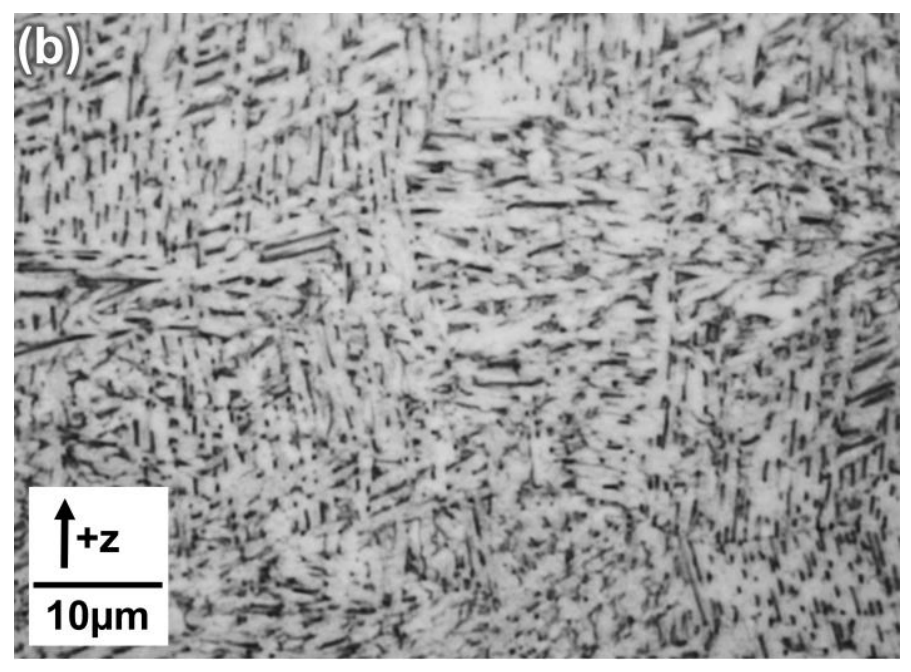

Page 26 of 41 


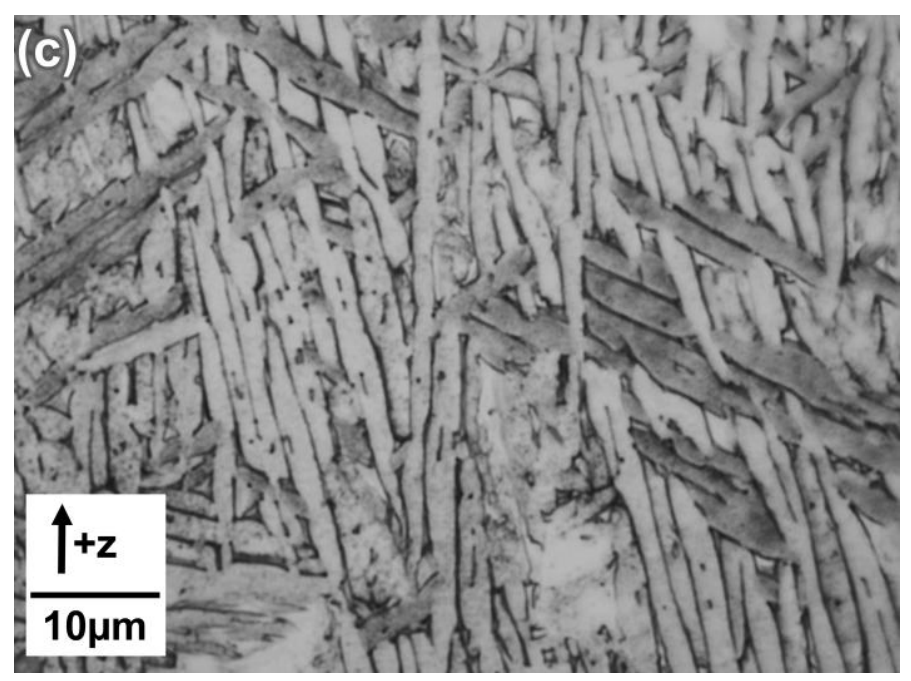

Page 27 of 41 


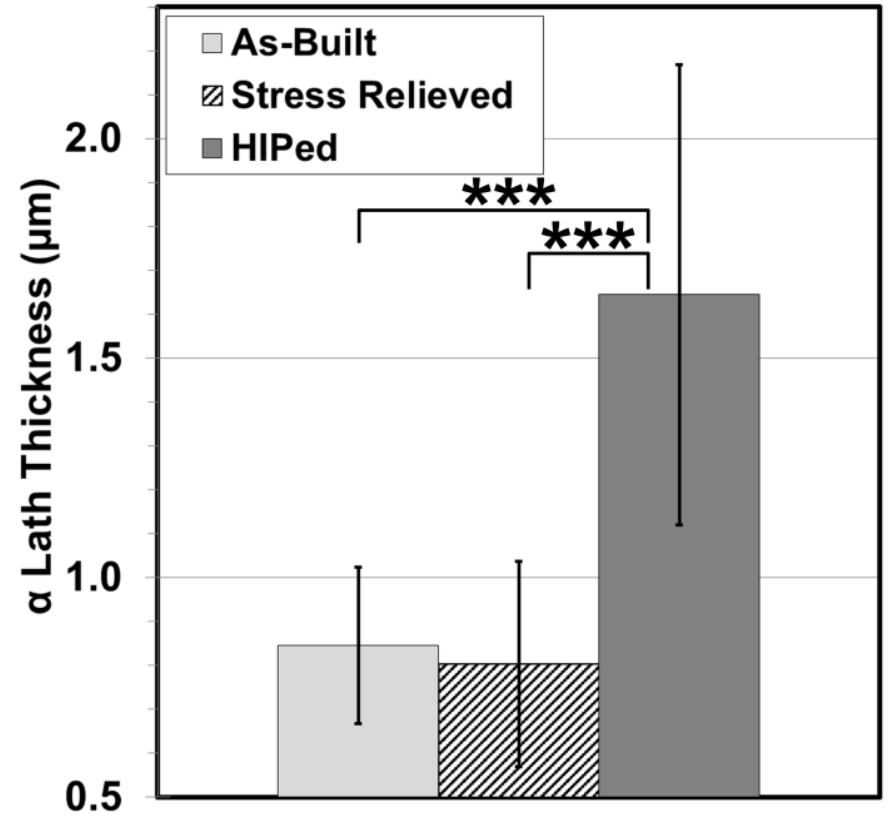

Page 28 of 41 


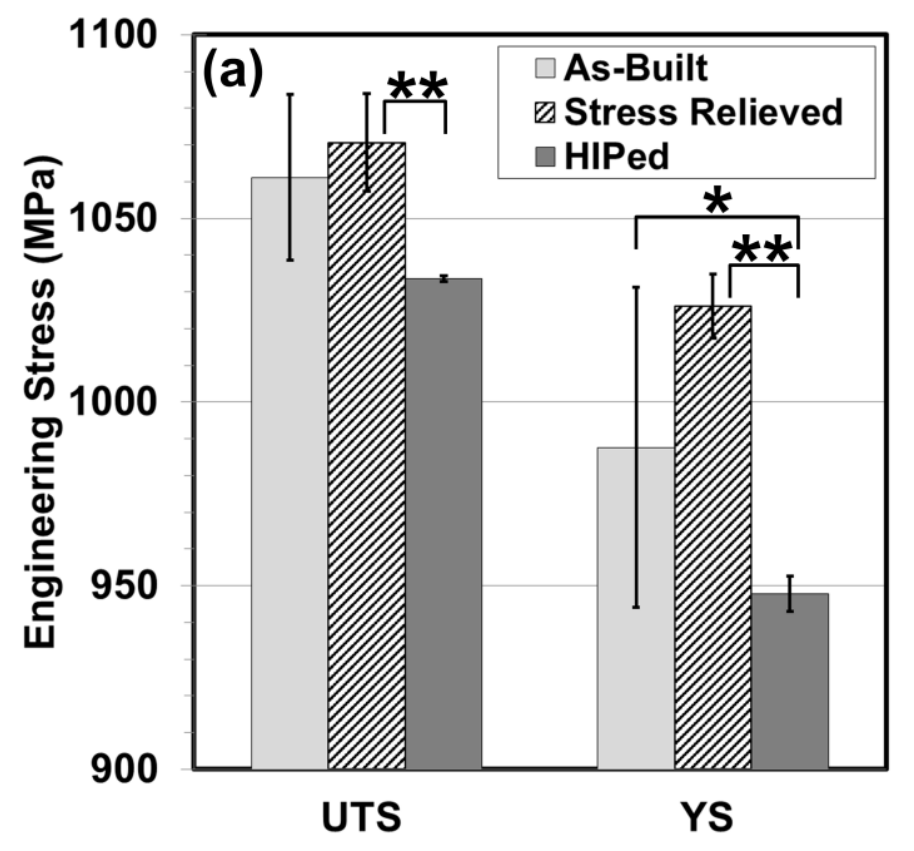

Page 29 of 41 


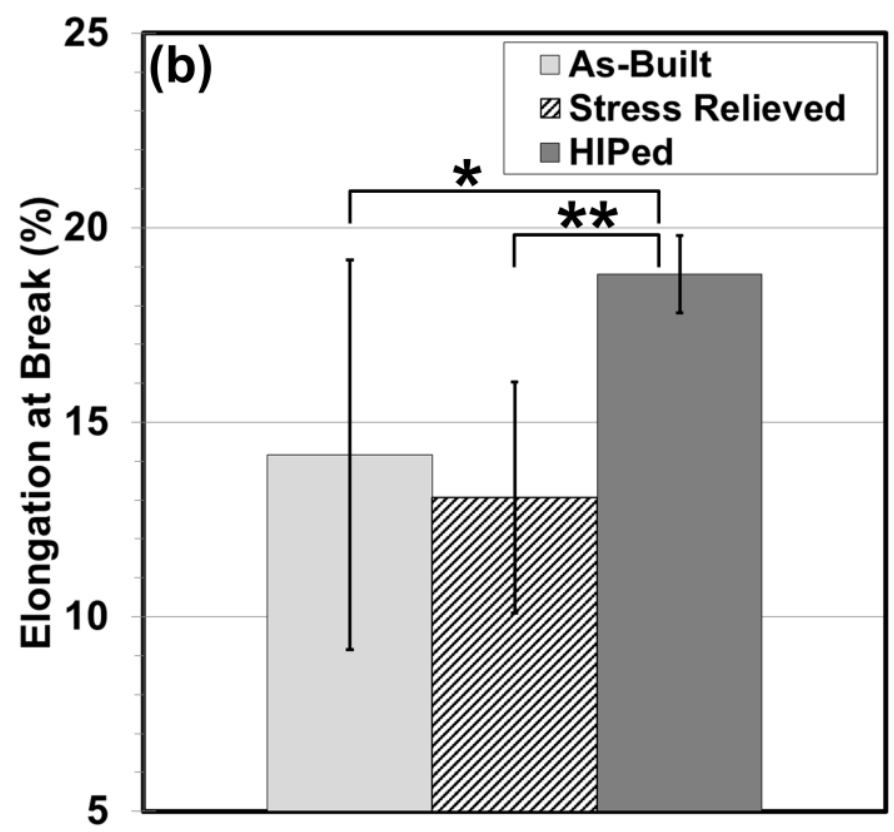

Page 30 of 41 


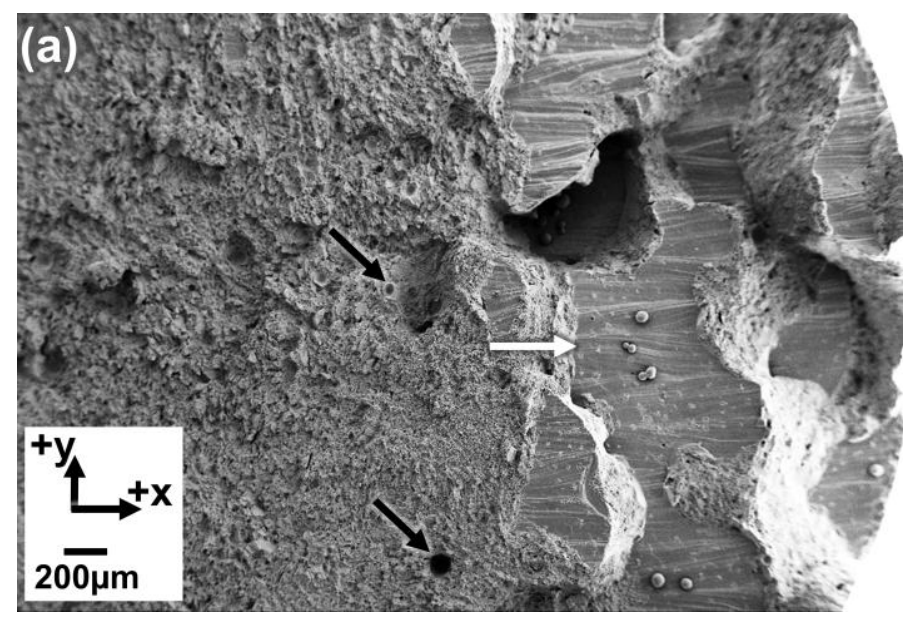

Page 31 of 41 


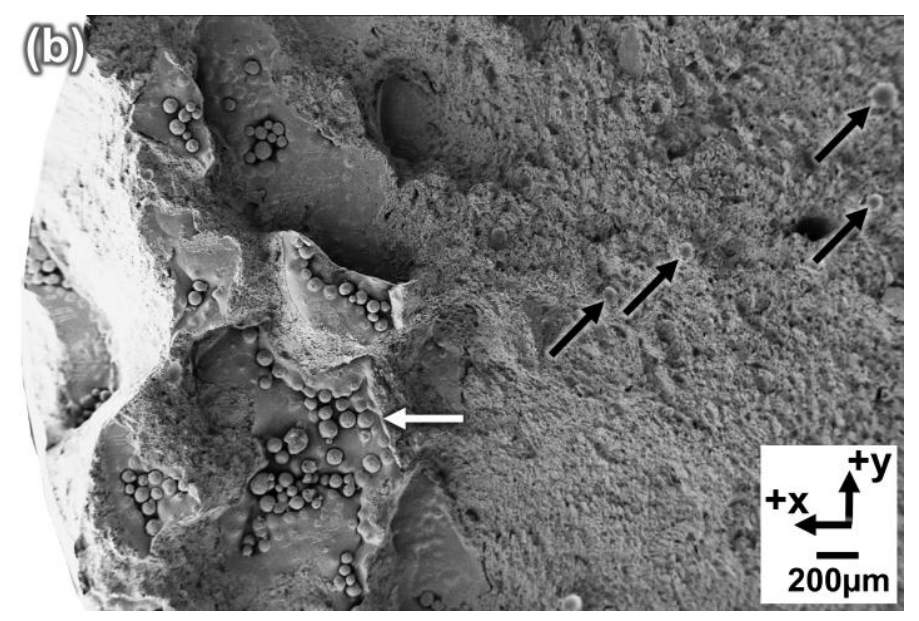

Page 32 of 41 


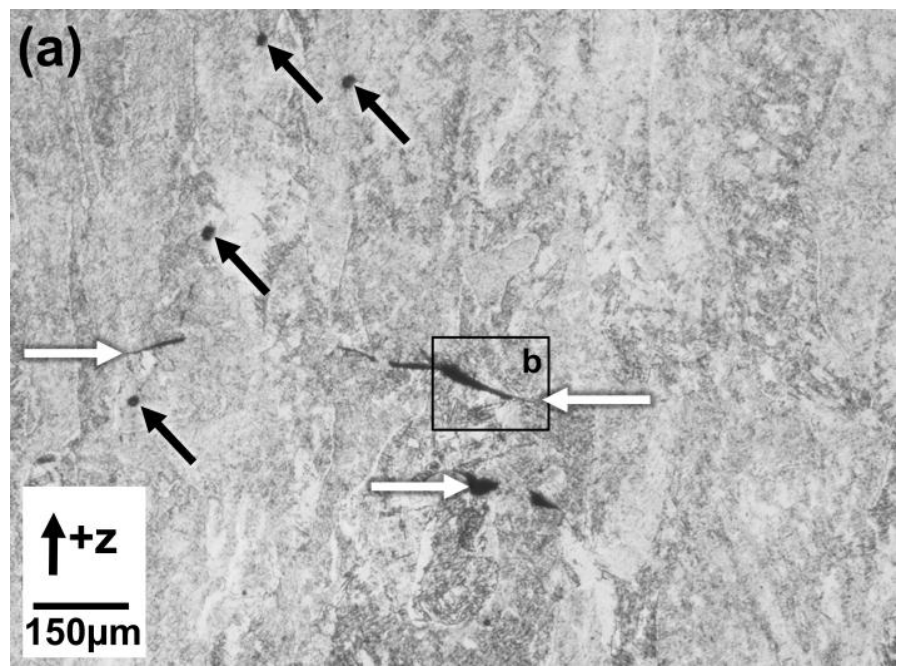

Page 33 of 41 
(b)

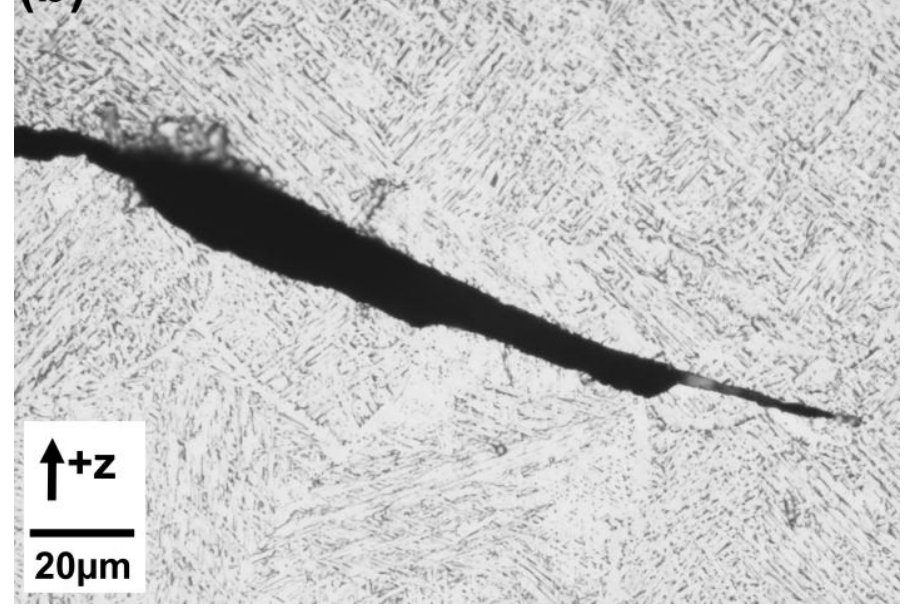

Page 34 of 41 


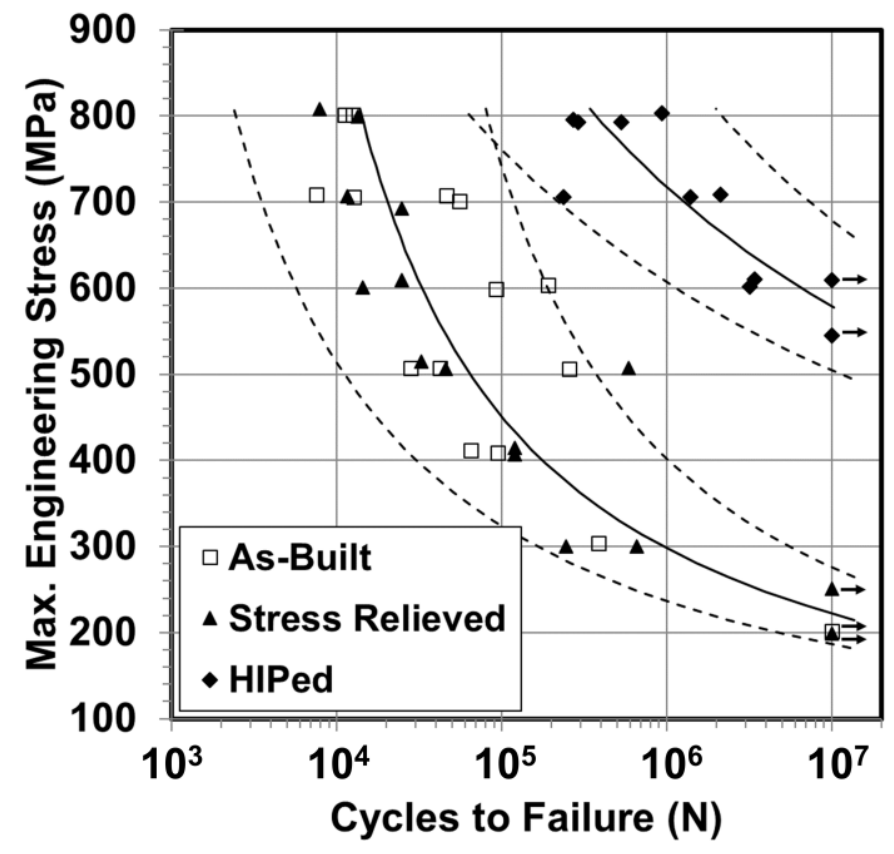

Page 35 of 41 


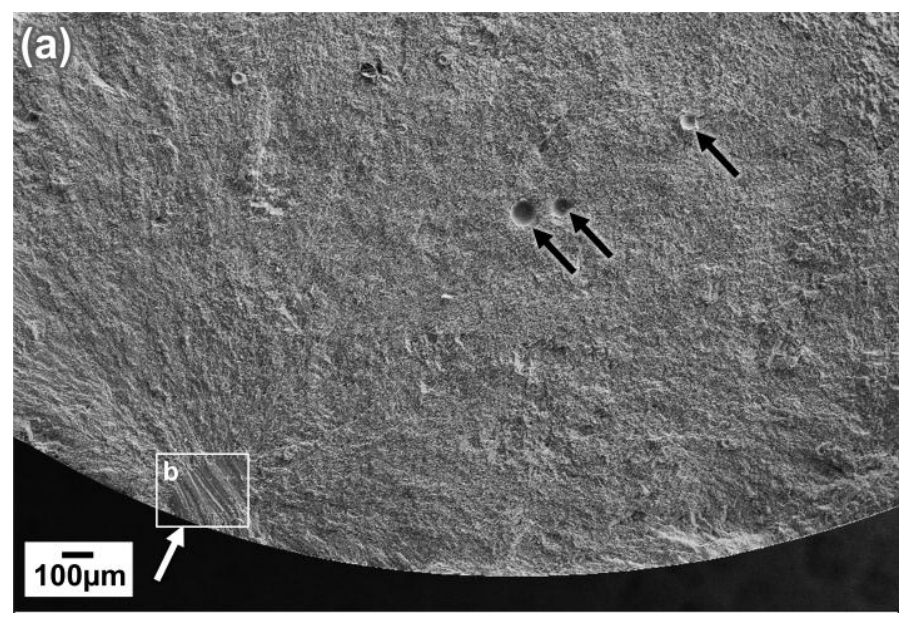

Page 36 of 41 


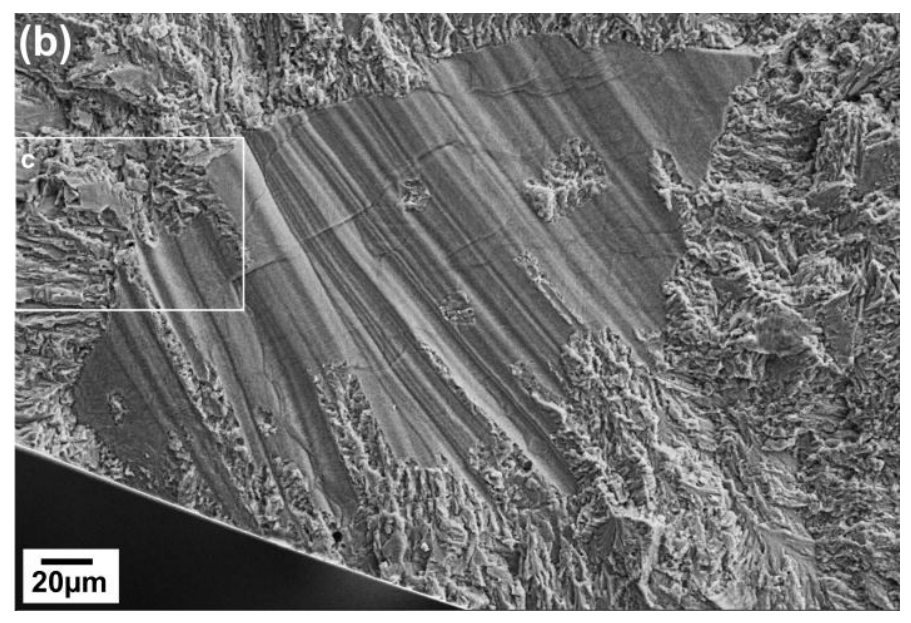

Page 37 of 41 


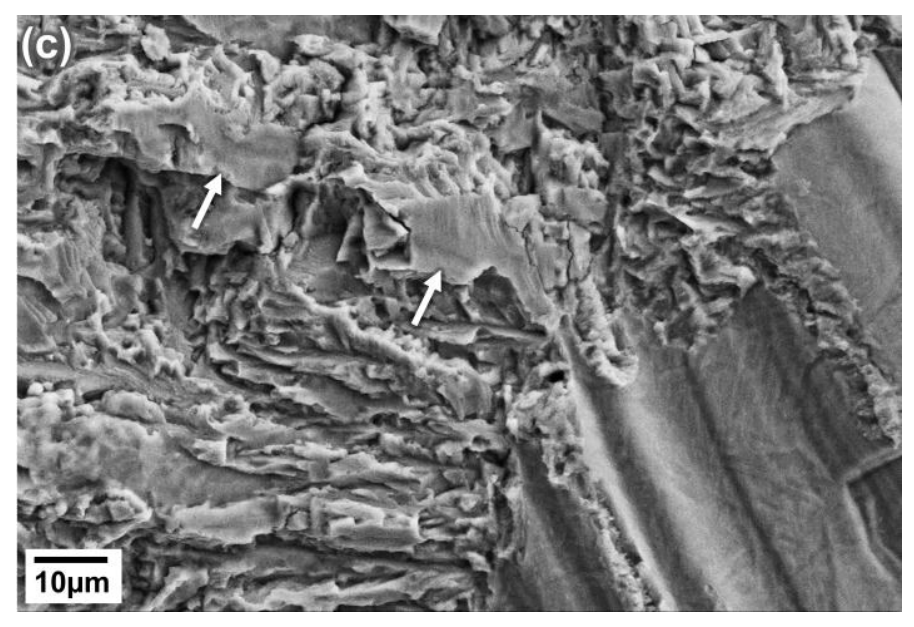

Page 38 of 41 


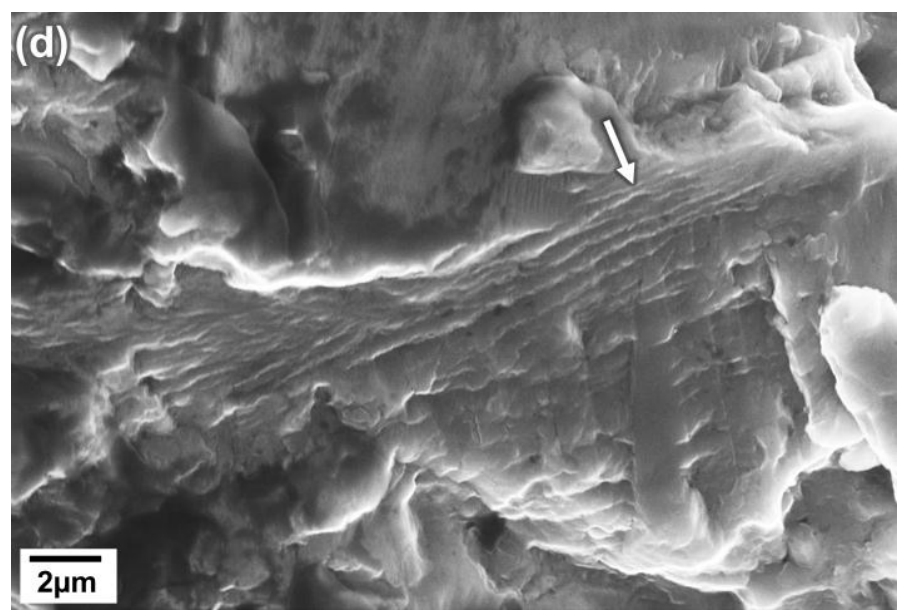

Page 39 of 41 


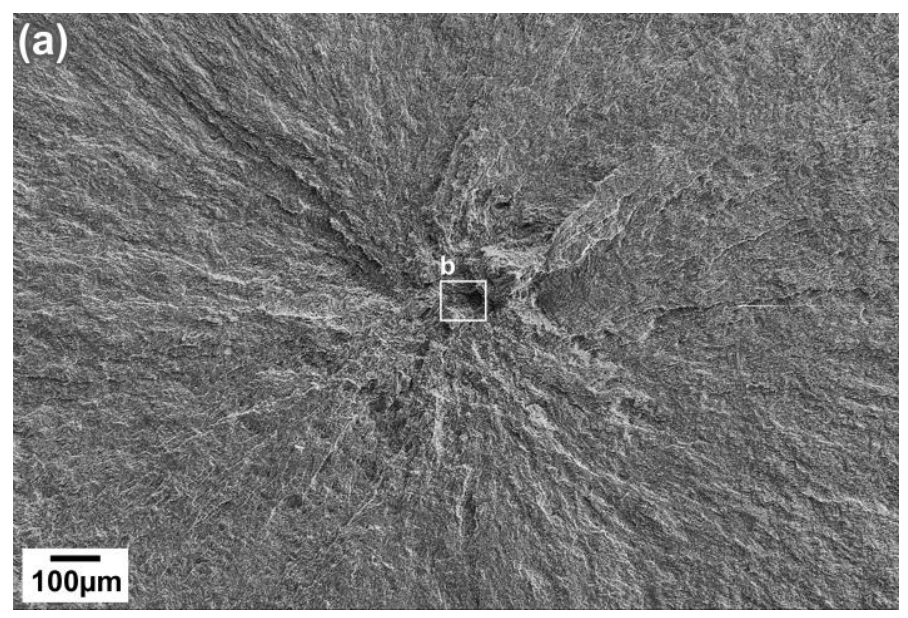

Page 40 of 41 


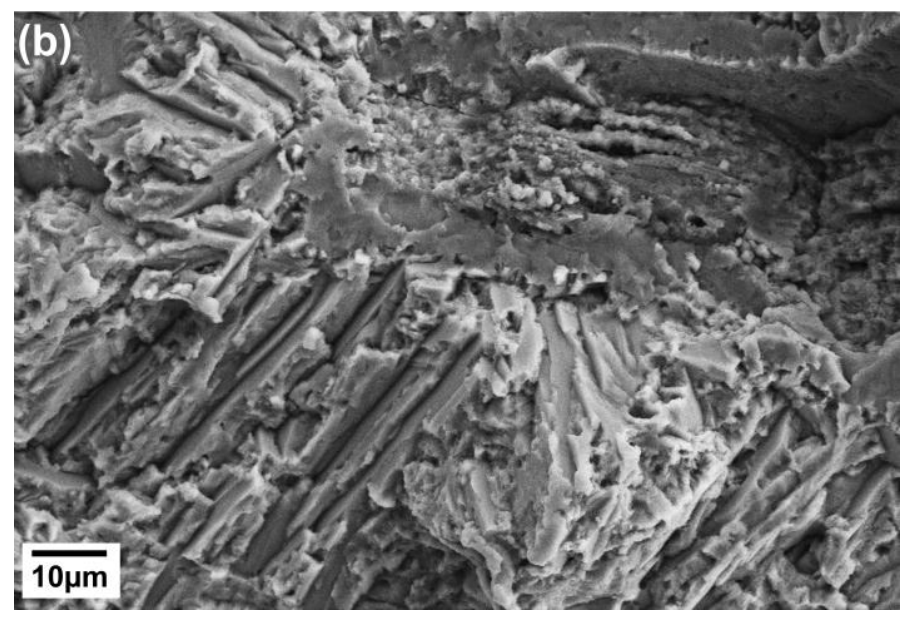

Page 41 of 41 


\begin{tabular}{|l|l|l|l|l|l|l|}
\hline & $\mathbf{N}$ & $\mathbf{C}$ & $\mathbf{H}$ & $\mathbf{F e}$ & $\mathbf{O}$ & Al \\
\hline ASTM F2924 & $0.05 \mathrm{max}$ & $0.10 \mathrm{max}$ & $0.015 \mathrm{max}$ & $0.30 \mathrm{max}$ & $0.20 \mathrm{max}$ & $5.5-6.75$ \\
\hline as-built & $0.054 \pm 0.008$ & $0.015 \pm 0.0009$ & $0.0003 \pm 0.00002$ & 0.2 & $0.191 \pm 0.006$ & 5.67 \\
\hline stress relieved & $0.053 \pm 0.007$ & $0.017 \pm 0.001$ & $0.0005 \pm 0.0003$ & 0.197 & $0.191 \pm 0.006$ & 5.78 \\
\hline HIPed & $0.055 \pm 0.008$ & $0.015 \pm 0.0009$ & $0.0008 \pm 0.00005$ & 0.2 & $0.191 \pm 0.006$ & 5.67 \\
\hline
\end{tabular}




\begin{tabular}{|c|c|c|c|c|c|}
\hline \multirow{2}{*}{ Condition } & $\begin{array}{c}x \text {-coordinate } \\
(\mathrm{mm})\end{array}$ & $\begin{array}{c}y \text {-coordinate } \\
(\mathrm{mm})\end{array}$ & \multicolumn{3}{|c|}{ Residual Stress (MPa) } \\
\cline { 3 - 6 } & -2 & 0 & 17 & 24 & 17 \\
\hline \multirow{5}{*}{ As-Built } & -2 & 4 & -8 & -17 & -3 \\
\cline { 2 - 6 } & 0 & 4 & 53 & 78 & 49 \\
\cline { 2 - 6 } & 0 & 0 & -38 & -60 & -55 \\
\cline { 2 - 6 } & -2 & 4 & -25 & -45 & -2 \\
\cline { 2 - 6 } & -4 & 0 & 20 & 15 & 40 \\
\hline \multirow{3}{*}{ Stress Relieved } & 0 & 0 & 20 & 7 & 3 \\
\cline { 2 - 6 } & 3.5 & 0 & -20 & -30 & -15 \\
\cline { 2 - 6 } & 0 & 3.5 & 12 & 2 & 21 \\
\hline \multirow{3}{*}{ HIPed } & 0 & 0 & -29 & -11 & -16 \\
\cline { 2 - 6 } & 0 & 4 & 15 & 22 & 24 \\
\hline
\end{tabular}




\begin{tabular}{|c|c|c|c|}
\hline Parameter & Estimate & Std. Error & $\boldsymbol{p}$ \\
\hline $\boldsymbol{b}_{0}$ & 4.211 & 2.214 & 0.0572 \\
\hline $\boldsymbol{b}_{1}$ & 8.533 & 1.9 & 0.00000707 \\
\hline $\boldsymbol{b}_{3}$ & 2.823 & 2.252 & 0.21 \\
\hline $\boldsymbol{b}_{4}$ & -6.032 & 1.912 & 0.00161 \\
\hline$\sigma$ & 0.866 & N/A & N/A \\
\hline
\end{tabular}

